\title{
SACCHARUM SPONTANEUM L. EVALUADA COMO SUSTRATO SÓLIDO ORGÁNICO NATURAL EN DESNITRIFICACIÓN BIOLÓGICA
}

\author{
Rodríguez, Luisa \\ Panamá, Panamá \\ luisarodg@gmail.com \\ Deago, Euclídes \\ Panamá, Panamá \\ euclides.deago@utp.ac.pa \\ Cueto, Gilberto \\ Panamá, Panamá \\ gilbertocuetobotello@yahoo.com \\ Jaramillo, Aris \\ Panamá, Panamá \\ aris_1629@hotmail.com
}

Universidad Tecnológica de Panamá- Centro de Investigaciones Hidráulicas e Hidrotécnicas

\begin{abstract}
Approximately $12 \%$ of the soil in the Republic of Panama is used for agricultural and industrial livestock activities, which has caused alterations in the Nitrogen Cycle, increasing nitrate levels in groundwater, wastewater and surface water. In the year 2000, nitrate concentrations exceeded $50 \mathrm{mg} / \mathrm{L}$ [ 9 ] by $20 \%$ and $60 \%$; this imbalance is the cause of serious health problems, in addition to damage to the aquatic ecosystem. An efficient alternative for the removal of this compound is Natural Solid Organic Substrates (NSOS) as a source of organic carbon for the denitrification process. Our study uses Canal Straw (Saccharum Spontaneum L.) as NSOS to reduce nitrate concentrations present in water. The harvesting took place at the Technological University of Panama, bromatological tests and leaching tests were carried out to determine the optimum section of the plant for the use of soluble carbon. In addition, we conducted batch tests to determine the total contribution of soluble carbon and the release rate. The results were encouraging with $99.85 \%$ nitrate removal at a release rate of $0.12 \mathrm{~d}$ - and the final contribution of $711 \mathrm{mg}$ COD. Nitrate removal is evident
\end{abstract}


until the depletion of carbon input by Saccharum s., this demonstrates the potential of the plant for this process. Further studies are required to establish its uses, since it represents a feasible alternative due to its low cost and easy access.

Keywords: Denitrification, nitrate, Saccharum spontaneum L., carbon release, electron donor.

\section{Resumen}

Aproximadamente el $12 \%$ del suelo de la República de Panamá es usado para actividades ganaderas agrícolas e industriales, esto ha causado alteraciones en el Ciclo de Nitrógeno presentando aumentos en los niveles de Nitrato presentes en las aguas subterráneas, residuales y superficiales. En el año 2000 las concentraciones de Nitrato sobrepasan los $50 \mathrm{mg} / \mathrm{L}$ [9] en un $20 \%$ y $60 \%$; este desequilibrio es causante de graves afecciones a la salud, además de los daños al ecosistema acuático. Una alternativa eficiente para la remoción de este compuesto son los Sustratos Sólidos Orgánicos Naturales (SSON) como fuente de carbono orgánico para el proceso de desnitrificación. Nuestro estudio utiliza la Paja Canalera (Saccharum Spontaneum L.) como SSON para reducir las concentraciones de nitrato presente en el agua. La cosecha se dio en la Universidad Tecnológica de Panamá, se realizaron ensayos bromatológicos, pruebas de lixiviación para determinar la sección optima de la planta para el aprovechamiento del carbono soluble. Además, realizamos pruebas Batch para determinar el aporte total de carbón soluble y la tasa de liberación. Los resultados fueron alentadores con $99.85 \%$ de remoción de Nitrato con tasa de liberación de 0.12 d-1 y el aporte final de $711 \mathrm{mg}$ de DQO. La eliminación del Nitrato es evidente hasta el agotamiento del aporte de carbono por la Saccharum s., esto demuestra el potencial de la planta para este proceso. Se requiere profundizar en más estudios para establecer sus usos, ya que, representan una alternativa factible por su bajo costo y fácil acceso.

Palabras claves: Desnitrificación, Nitrato, Saccharum spontaneum L., liberación de carbono, donante de electrones.

\section{INTRODUCCIÓN}

La ingesta de agua que contenga más de $50-100 \mathrm{mg} / \mathrm{L}$ de nitratos (como ion nitrato) puede producir metahemoglobinemia en lactantes menores de un año (trastorno sanguíneo relacionado con el transporte y liberación de oxígeno) y cáncer en el tubo digestor de los consumidores. Por consiguiente, el valor de referencia para el nitrato es de $50 \mathrm{mg} / \mathrm{L}$ y se 
establece $3 \mathrm{mg} / \mathrm{L}$ como valor de referencia para nitrito en exposiciones a corto plazo.

La desnitrificación mediante el uso de sustratos sólidos como alternativa de fuente de carbono ha sido empleada durante los últimos años por varios investigadores; entre algunos estudios están los realizados con algodón, paja de trigo, polihidroxialcanoatos (PHAs), y polycaprolactone (PCL), Saccharum spontaneum L. [3] [11] [5] [13]

Existen dos tipos de fuentes de carbono sólidos disponibles para la desnitrificación: los polímeros biodegradables sintéticos y Sustratos Sólidos Orgánicos Naturales (SSON).

Los materiales naturales son de bajo costo y alta disponibilidad, pero presentan altas concentraciones de DQO y color en el efluente, especialmente durante el periodo de puesta en marcha. [12] [1] [8] [2] [1]

A través de esta investigación enfatizamos lo necesario que es realizar el proceso de desnitrificación, como parte del tratamiento terciario que se le dan a las aguas residuales, de una manera económica y eficaz, mediante el uso de SSON como la Saccharum spontaneum L. para realizar este tipo de tratamientos.

\section{MÉTODOS}

\section{A. COLECTA Y SELECCIÓN DEL SUSTRATO}

La Saccharum spontaneum L. tiene como característica principal es su facultad de crecer en áreas abiertas, áreas deforestadas o en suelos infértiles. Es resistente a las sequías prolongadas o períodos largos de lluvia o incluso inundaciones.

Su producción de biomasa es una de las más altas que se conocen; al ser una planta de metabolismo C4, su única limitación es que no crece en sombra. Las mencionadas características facilitaron su uso para el control de la erosión y estabilización de taludes en la zona del Canal. [6]

Para este estudio realizamos tres (3) cosechas en el Campus de la Universidad Tecnológica de Panamá durante los meses de prueba a inicio y a mediados de la estación lluviosa en Panamá, cosechamos espigas de aproximadamente dos (2) y tres (3) metros de longitud, seguidamente se retiraron las hojas, la parte superior y la inferior del tallo para trabajar con la parte media de la planta.

La parte media (figura 1) es óptima para llevar a cabo los ensayos; esto fue determinado por una serie de pruebas bromatológicas que se realizaron a las tres (3) secciones del tallo. [4] 


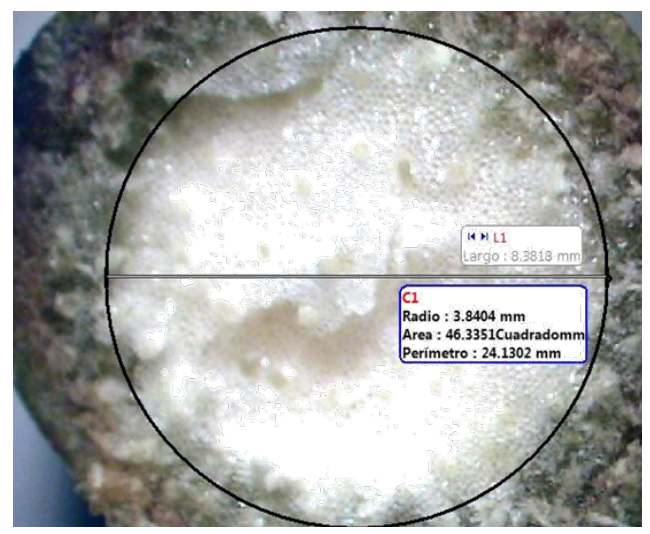

Fig.1 Sección media de la Saccharum spontaneum L. tomada con un estereoscopio.

\section{B. ENSAYOS}

\section{- Lixiviación:}

Este ensayo de ocho (8) días se determina la capacidad de liberación del material orgánico utilizado, S. spontaneum L. se establecerá el aporte carbono/ nitrógeno, la demanda bioquímica de oxígeno, entre otros componentes.

La sección media de la gramínea se recorta en trozos de $1 \mathrm{~cm}$; para el aprovechamiento total de los nutrientes contenidos. [4]

Para el ensayo se utilizaron 10 trozos de $1 \mathrm{~cm}$ de la sección optima, los cuales fueron esterilizados exponiéndolos a luz ultravioleta con longitud de onda de $365 \mathrm{~mm}$ durante veinte (20) minutos de cada lado.

La muestra fue preparada con el sistema OxiTop, conteniendo $200 \mathrm{ml}$ de agua a temperatura de $23^{\circ} \mathrm{C}$, siendo el rango ideal entre $20^{\circ} \mathrm{C}$ y $30^{\circ} \mathrm{C}$ y el material detrítico previamente esterilizado.

Se realizaron pruebas de Ph, turbiedad, sólidos suspendidos, Nitrato, Nitrito, DQO y Amonio.

\section{- Batch Biológico:}

Con esta prueba podemos conocer el comportamiento de la liberación de carbono desde la S. spontaneum L. en condiciones anóxicas; a partir de esto podremos determinar la tasa de desnitrificación.

Para este ensayo utilizamos $24 \mathrm{~g}$. de material detrítico con la finalidad de comparar estudios previos realizados con $12 \mathrm{~g}$ [5] y $13 \mathrm{~g}$ [4].

El material fue vertido en tres (3) reactores con un volumen de $500 \mathrm{ml}$ de agua destilada, dosificados con $100 \mathrm{mg}$ de N-NO3/L utilizando NaNO3. Cada reactor fue expuesto a 10 minutos de nitrógeno gaseoso con la finalidad de reducir el oxígeno disuelto, manteniendo una concentración menor de $2.00 \mathrm{mg} / \mathrm{L}$

Las muestras se mantuvieron agitadas constantemente mediante un sistema de agitación 
magnético. Además, fue necesario el periodo de aclimatación de 2 semanas para estabilizar las condiciones del sistema.

Posterior a la aclimatación de las bacterias se tomaron muestras diarias para monitorear parámetros como pH, Potencial Redox, Conductividad, Sólidos Suspendidos totales, Nitrato, Nitrito, Temperatura, DQO y Amonio. Una vez iniciado el período de muestreo se volvía a dosificar nitrato cada dos días o cuando el mismo se hubiera consumido en su mayoría. Previo a realizar las pruebas de nitrato, nitrito y amonio las muestras eran filtradas con filtros de celulosa de $45 \mu \mathrm{m}$.

\section{RESULTADOS}

\section{A. ENSAYO DE LIXIVIACIÓN}

A consecuencia de la hidrólisis se da la liberación de DQO inmediata en el primer día de muestreo (Figura 2), luego ocurre la liberación prolongada hasta el punto de agotamiento total. La tasa de liberación de carbono obtenida es de $2.11 \mathrm{~d}-1$ y el aporte máximo de DQO acumulado en el sobrenadante fue de $711 \mathrm{mg}$, esto producto de $10 \mathrm{~g}$ de material seco.

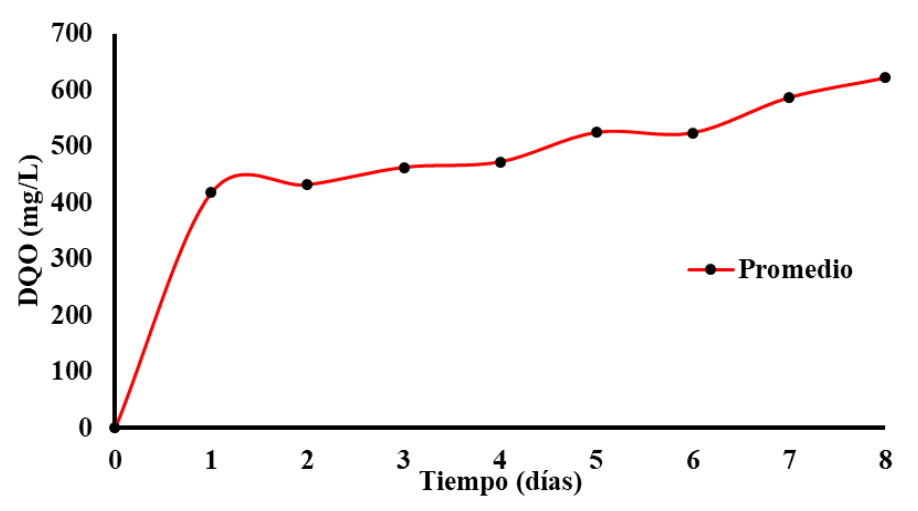

Fig.2 Comportamiento de la DQO.

\section{B. ENSAYO BATCH BIOLÓGICO}

Los reactores Batch fueron promediados para mostrar los resultados del comportamiento observado de los parámetros físico- químicos; la duración de este ensayo fue de 31 días, periodo en el cual se cumplió con los rangos óptimos.

Las bacterias heterótrofas facultativas deben estar en estado anóxico para su crecimiento, supervivencia y para llevar a cabo el proceso de desnitrificación efectivo, para esto se requiere, preferiblemente, de valores negativos. [7]

Durante el muestreo, las mediciones críticas obtenidas representan el $50 \%$ de la remoción de nitrato (gráfico 6) degradado con respecto a la concentración inicial dosificada. 
Al degradar el nitrato se producen dos compuestos, nitrito y amonio. Los valores obtenidos para el nitrito no sobrepasan los $0.7 \mathrm{mg} / \mathrm{L}$ (figura 3) por lo que podemos considerar las concentraciones de este como bajos y no significativos.

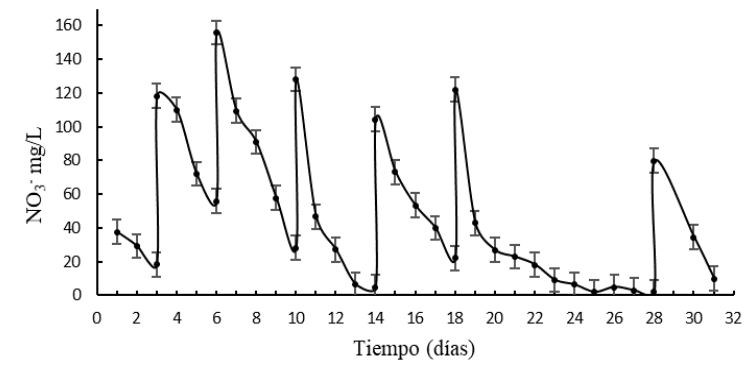

Fig. 3 Comportamiento de la degradación de Nitrato Se dosificaron $100 \mathrm{mg} / \mathrm{L}$ de NaNO_3 a cada reactor.

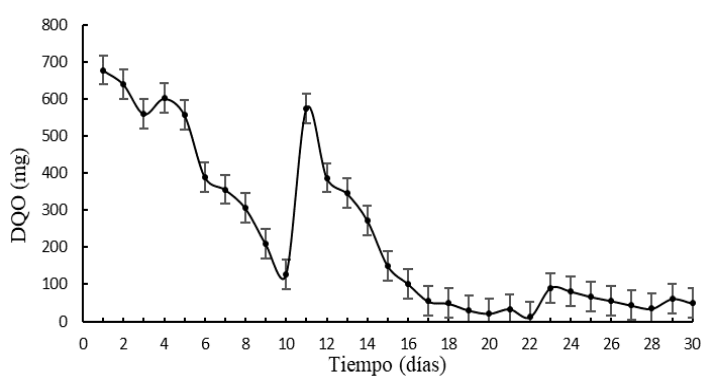

Fig. 4 Comportamiento del DQO en el sobrenadante del ensayo Batch.

En la figura 4 podemos notar un aumento inusual el día 11 a causa del cambio en ciertos trozos de material descompuesto prematuramente, por lo que podremos observar a partir de este día, mayor liberación de DQO, pero en los próximos días observamos el mismo comportamiento que se dio a inicios del ensayo hasta el agotamiento.

- CONSTANTE DE LIBERACIÓN Y TASA DE DESNITRIFICACIÓN

Se utilizó el método de mínimos cuadrados, usando los valores de la DQO total acumulada tanto para el ensayo Batch como para el sistema para obtener la constante de liberación.

La constante obtenida para el reactor Batch es de $0.12 \mathrm{~d}-1$ y está dentro del rango de valores obtenidos del proceso de degradación anaerobia con gramíneas. [10]

$$
\begin{gathered}
R_{D}=\frac{c_{i}-c_{e}}{t_{r}} R_{D}=\frac{c_{i}-c_{e}}{t_{r}} \quad \text { EC. } 1 \\
\mathrm{Ci}=\text { Concentración inicial (mg/L NO3-) } \\
\mathrm{Ce}=\text { Concentración final (mg/L NO3-) } \\
\text { tr=tiempo de remoción (horas) }
\end{gathered}
$$

\begin{tabular}{|c|c|}
\hline DATOS & BATCH \\
\hline $\begin{array}{c}\text { Concentración Inicial (mg/L } \\
\left.\mathrm{NO}_{3}^{-}\right)\end{array}$ & 121.1 \\
\hline Concentración Final $\left(\mathrm{mg} / \mathrm{L} \mathrm{NO}_{3}{ }^{-}\right)$ & 35.6 \\
\hline Tiempo de remoción (horas) & 24 \\
\hline $\begin{array}{c}\text { Tasa de desnitrificación } \\
\frac{m g}{L * h} \mathrm{~N}-\mathrm{NO}_{3}^{-} \frac{m g}{L * h} \mathrm{~N}-\mathrm{NO}_{3}^{-}\end{array}$ & 3.56 * \\
\hline
\end{tabular}

Tabla 1. Tasa de Desnitrificación

En términos de remoción por día $86.9 \mathrm{mg} / \mathrm{L}^{*} \mathrm{~d}$ 


\section{CONCLUSIONES}

Utilizando la paja canalera como SSON se proporciona un sistema eficiente, sostenible y ayuda a la erradicación de la gramínea que es considerada agresiva al ecosistema.

En el ensayo de lixiviación se registraron altas concentraciones de carbono orgánico soluble, durante la fase de liberación hidrolítica del material confirmando el uso efectivo de la planta como donante de carbono.

La participación en conjunto tanto de bacterias heterótrofas facultativas como de la S. spontaneum, dentro de un sistema Batch biológico, funciona de manera eficiente para remover el $70.6 \%$ del Nitrato, bajo condiciones anóxicas y aportando $69.60 \mathrm{mg} / \mathrm{L}^{*} \mathrm{~d}$ equivalentes a una masa de $711 \mathrm{mg}$ de DQO durante todo el proceso, es aceptable en comparación con otros autores.

\section{REFERENCIAS}

[1] Aslan, S., Turkman, A.,(2004) Simultaneous biological removal of dosulfan $(\alpha+\beta)$ and nitrates from drinking waters using wheat straw as substrate. Environment International; pp: 449-455.

[2] Cameron, SG. \& Schipper, LA. (2012). Hydraulics properties, hydraulic efficiency and nitrate removal of organic carbon media for use in desnitrification beds. Ecological Engineering, 41, 1-7.

[3] Chu, LB., Wang JL., (2016). Biological nitrate removal from water and wastewater by solid- phase desnitrification process. Biotechnology advance; pp: 1 -9.

[4] Cueto G., Jaramillo A., (2017) Diseño preliminar de columnas de filtración según resultados experimentales de ensayos batch de desnitrificación con Saccharum Spontaneum L. como fuente de carbono; Universidad Tecnológica de Panamá; pp. 92-94.

[5] Deago, Euclides M. y Pizarro, Gonzalo E. (2014). Desnitrificación del agua Potable usando Saccharum spontaneum L. como un Sustrato Sólido Orgánico Natural.

[6] Esquivel E. (2004) El origen de la Paja Canalera, S. spontaneum L. en Panamá. Agrociencia Panamensis, No. 34, año III.

[7] Morales M. (2014). Transcripción de Potencial Redox y su efecto en el crecimiento microbiano. Recuperado de: https://prezi.com/q3ikqhv2chva/potencial-redox-y-su-efecto-en-el-crecimientomicrobiano/ 30/05/2021

[8] Roberton, WD., (2010) Nitrate removal rates in woodchip media of varying age. Ecol. Eng. 36(11), 1581-1587.

[9] Organización Mundial de la Salud (2006). Guías para la calidad del agua potable incluye el primer apéndice. Vol. 1: Recomendaciones. Tercera edición; disponible en: http://www.who.int/water_ sanitation_health/dwq/gdwq3_es_fulll_lowsres.pdf 21/05/2021

[10] Veeken, A., \& Hamelers, B. (1999). Effect of temperature on hydrolysis rates of selected biowaste components. Bioresource Technology, 69(3), 249-254

[11] Volokita, M., Abeliovich, A., \& Soares, M. I. M. (1996a). Denitrification of groundwater using cotton as energy source. Water Science and Technology, 34(1-2), 379-385.

[12] Volokita, M., Belkin, S., Abeliovich, A., \& Soares, M. I. M. (1996b). Biological denitrification of drinking water using newspaper. Water Research, 30(4), 965-971. 
[13] Xu, Z. X., Shao, L., Yin, H. L., Chu, H. Q., \& Yao, Y. J. (2009). Biological Denitrification Using Corncobs as a Carbon Source and Biofilm Carrier. Water Environment Research, 81(3), 242-247.

\section{AUTORIZACIÓN Y LICENCIA CC}

Los autores autorizan a APANAC XVIII a publicar el artículo en las actas de la conferencia en Acceso Abierto (Open Access) en diversos formatos digitales (PDF, HTML, EPUB) e integrarlos en diversas plataformas online como repositorios y bases de datos bajo la licencia CC:

Attribution-NonCommercial-ShareAlike 4.0 International (CC BY-NC-SA 4.0) https://creativecommons. org/licenses/by-nc-sa/4.0/.

Ni APANAC XVIII ni los editores son responsables ni del contenido ni de las implicaciones de lo expresado en el artículo. 